\title{
STUDY OF AFRICAN DUST WITH MULTI-WAVELENGTH RAMAN LIDAR DURING "SHADOW" CAMPAIGN IN SENEGAL
}

\author{
Igor Veselovskii ${ }^{1}$, Philippe Goloub ${ }^{2}$, Thierry Podvin $^{2}$, Valentyn Bovchaliuk ${ }^{2}$, Didier Tanre ${ }^{2}$, Yevgeny \\ Derimian $^{2}$, Mikhail Korenskiy $^{1}$, Oleg Dubovik $^{2}$ \\ ${ }^{1}$ Physics Instrumentation Center, Troitsk, Moscow Region, 142190, Russia \\ E-mail: igorv@pic.troitsk.ru \\ ${ }^{2}$ Laboratoire d'Optique Atmosphérie, Université de Lille-CNRS, 59650, Villeneuve d'Ascq
}

\begin{abstract}
West Africa and the adjacent oceanic regions are very important locations for studying dust properties and their influence on weather and climate. The SHADOW (Study of SaHAran Dust Over West Africa) campaign is performing a multi-scale and multi-laboratory study of aerosol properties and dynamics using a set of in situ and remote sensing instruments at an observation site located at IRD (Institute for Research and Development) Center, Mbour, Senegal $\left(14^{0} \mathrm{~N}, 17^{0} \mathrm{~W}\right)$. In this paper, we present the results of lidar measurements performed during the first phase of SHADOW which occurred in March-April, 2015. The multiwavelength MieRaman lidar acquired $3 \beta+2 \alpha+1 \delta$ measurements during this period. This set of measurements has permitted particle intensive properties such as extinction and backscattering Ångström exponents (BAE) for $355 / 532 \mathrm{~nm}$ wavelengths corresponding lidar ratios and depolarization ratio at $532 \mathrm{~nm}$ to be determined. The backscattering Ångström exponent during the dust episodes decreased to $\sim-0.7$, while the extinction Ångström exponent though being negative, was greater than -0.2. Low values of BAE can likely be explained by an increase in the imaginary part of the dust refractive index at $355 \mathrm{~nm}$ compared to 532 nm.
\end{abstract}

\section{INTRODUCTION}

Africa is one of the major sources of atmospheric dust and numerous campaigns were organized to study the dust properties near the origin source $[1,2,3]$. The SHADOW (Study of SaHAran Dust Over West Africa) campaign is performing a multiscale and multi-laboratory study of aerosol properties and dynamics using a set of in situ and remote sensing instrumentation (multi-wavelength Raman LIDAR, Wind-LIDAR,, nephelometer, aethalometer, sun/lunar photometer, airborne sunphotometer, optical particle counter) in the framework of the CaPPA (Chemical and Physical Processed in The Atmosphere) project (http://www.labex-cappa.fr/). The site is located at IRD (Institue for Research and
Development) Center, Mbour, Senegal $\left(14^{0} \mathrm{~N}, 17^{0} \mathrm{~W}\right)$. The objective of the experiment is to report the optical, chemical and physical properties of the aerosols as well as the source apportionment in a location where aerosol loading can be very large and aerosol type depends on the season. Two enhanced observing periods of 7 weeks are considered: MarchApril 2015 when dust originating from the Sahara/Sahel region is dominant and December 2015-January 2016 when dust and carbonaceous aerosols resulting from fire activities are in variable proportion and transported at different altitudes. Other types of aerosols can also be present such as sulfates from nearby urban areas or maritime aerosols depending on the air mass flow. The mixed state of these various chemical components results in different radiative properties of the aerosols.

We hereinafter focus our study on multiwavelength Mie-Raman lidar measurements performed during the first phase of the SHADOW campaign for the period 8 March - 24 April. During this period approximately 40 day- and night-time measurement sessions were performed and numerous strong dust episodes were observed.

\section{LIDAR SYSTEM DESCRIPTION}

The results presented were obtained with LILAS multi-wavelength Mie-Raman lidar based on a tripled Nd:YAG Spectra Physics INDI laser with a $20 \mathrm{~Hz}$ repetition rate. The laser output power at $\lambda=355 \mathrm{~nm}$ is about $2 \mathrm{~W}$. The backscattered light is collected by a $40-\mathrm{cm}$ aperture Newton telescope operated at $47 \mathrm{dg}$ to horizon. The system is capable of detecting three backscattered signals at the laser wavelengths and two Raman signals, thus three backscattering and two extinction coefficients (so called $3 \beta+2 \alpha$ set) can be calculated. The outputs of the detectors are recorded at $7.5 \mathrm{~m}$ range resolution using Licel transient recorders that incorporate both analog and photoncounting electronics. The full geometrical overlap of the laser beam and the telescope FOV is achieved at $\sim 1500 \mathrm{~m}$ range, which determines the lower limit of the full set of our $3 \beta+2 \alpha$ measurements due to the 
difficulty of calculating aerosol extinction in the overlap region. To improve the system operational capabilities, we detected rotational Raman scattering at $530 \mathrm{~nm}$ instead traditionally used vibrational nitrogen backscatter at $608 \mathrm{~nm}$. [4]. For each profile 4000 laser pulses were accumulated so the temporal resolution of the measurements was about 3 minutes. The measurements were performed both in day and night time. The system has also capability for depolarization measurements at $355 \mathrm{~nm}$ and $532 \mathrm{~nm}$ wavelengths.

\section{DUST PARTICLE PROPERTIES DERIVED FROM RAMAN LIDAR OBSERVATIONS}

The vertical distribution of particle intensive properties is strongly influenced by the origin of the air masses which during the SHADOW measurement period were arriving either from ocean or continental regions. In this section, we present the results of three measurements sessions on 13 and 29 March which were characterized by different types of air masses.

\section{March}

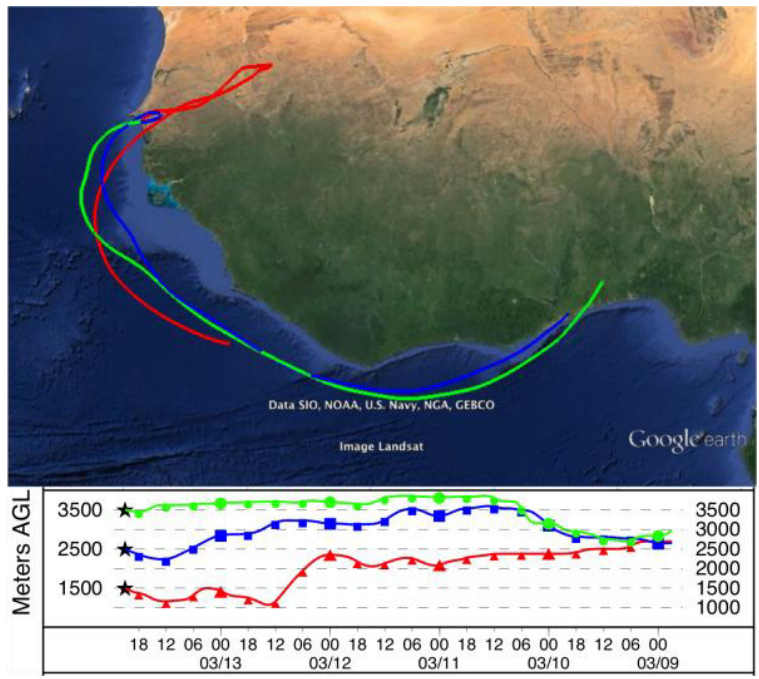

Fig.1. Five-day backward trajectories for the air mass in Mbour at altitudes $1500 \mathrm{~m}, 2500 \mathrm{~m}, 3500 \mathrm{~m}$, on 13 March 2015 at 21:00 UTC.

As follows from fig.1, on 13 March the air masses at all heights were transported mainly over the ocean, but the back trajectory for $1500 \mathrm{~m}$ presents a "loop" over continent, so the corresponding air masses may contain more dust compared to other heights. Fig.2 shows the vertical profiles of $3 \beta+2 \alpha$ measurements together with lidar ratios $\mathrm{LR}_{355}, \mathrm{LR}_{532}$, depolarization ratio $\delta_{532}$, and Angstrom exponents $A_{355 / 532}^{\alpha}, A_{355 / 532}^{\beta}$ on 13 March 2015. The aerosol layer extended up to $3500 \mathrm{~m}$ but the extinction coefficient $\alpha$ was relatively small; at both 355 and $532 \mathrm{~nm}$ wavelengths it did not exceed $0.16 \mathrm{~km}^{-1}$. The particle depolarization ratio at
$532 \mathrm{~nm}$ was approximately $31 \pm 4.5 \%$ inside the dust layer (up to $\sim 2750 \mathrm{~m}$ ) and decreased to less than $15 \%$ at $3250 \mathrm{~m}$. Likewise, the $A_{355 / 532}^{\alpha}$ and $A_{355 / 532}^{\beta}$ are close to zero up to $2750 \mathrm{~m}$, but above that height both EAE and BAE start to increase indicating the presence of smaller particles. The lidar ratios $\mathrm{LR}_{355}$ and $\mathrm{LR}_{532}$ are approximately $53 \pm 8$ sr inside the dust layer. Above $2750 \mathrm{~m}$ uncertainties are larger but the mean values of LR do not seem to change above the $2750 \mathrm{~m}$ height.
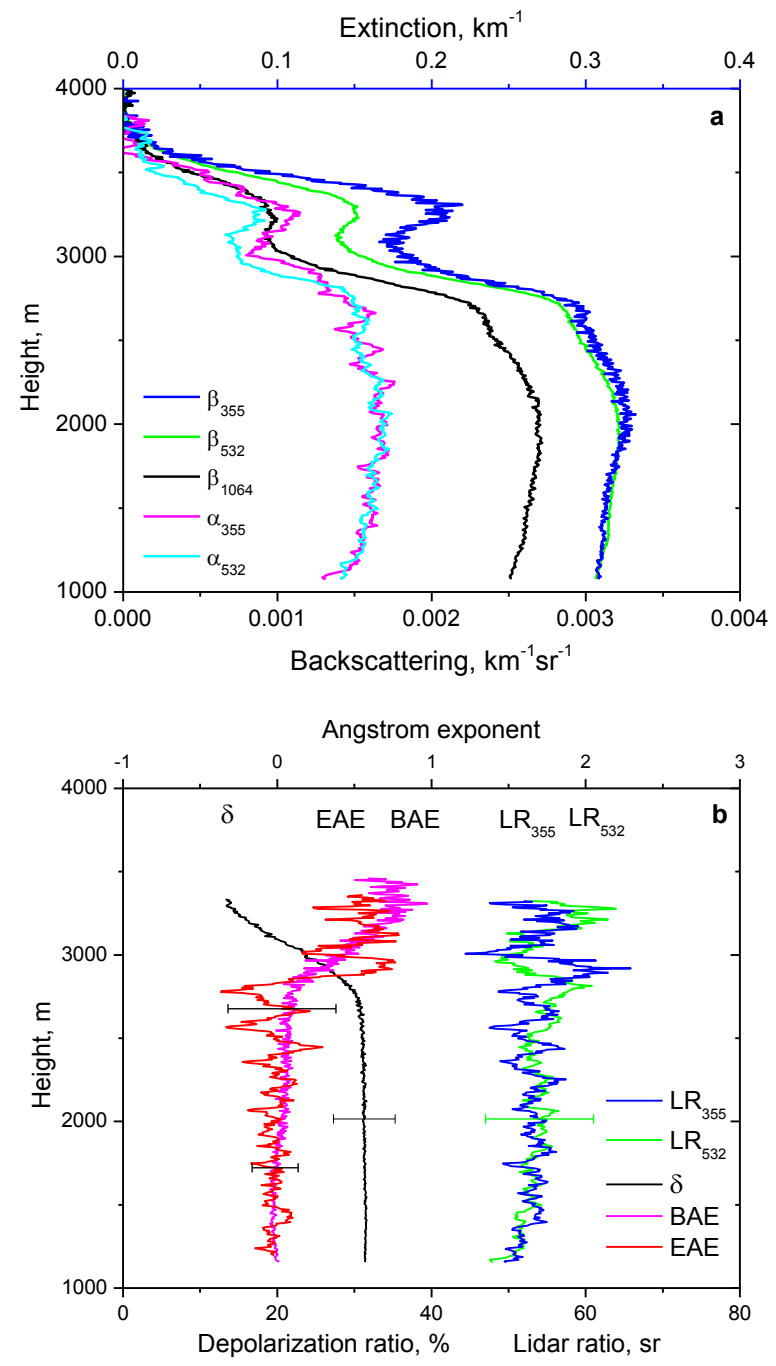

Fig.2. Vertical profiles of (a) backscattering and extinction coefficients and (b) lidar ratios, depolarization ratio, backscattering and extinction Angstrom exponents at 355/532 nm measured on 13 March 2015 for period 20:3021:30 UTC.

\section{March}

The backtrajectories from the night of 29-30 March indicating a strong dust case are shown in Fig.3. The air masses at low altitude were transported over the 
continent and were strongly loaded with dust. Fig.4 presents the height profiles of the same particle parameters as in fig. 2 but for 29 March. The extinction coefficient inside the dust layer (below $1500 \mathrm{~m})$ is greater than $0.6 \mathrm{~km}^{-1}$ for both wavelengths. The backscattering coefficient at 355 $\mathrm{nm}$ inside the dust layer is lower than $\beta_{532}$ which is consistent with the lidar ratio at $355 \mathrm{~nm}$ being larger than that at $532 \mathrm{~nm}$ with values as large as $65 \mathrm{sr}$.

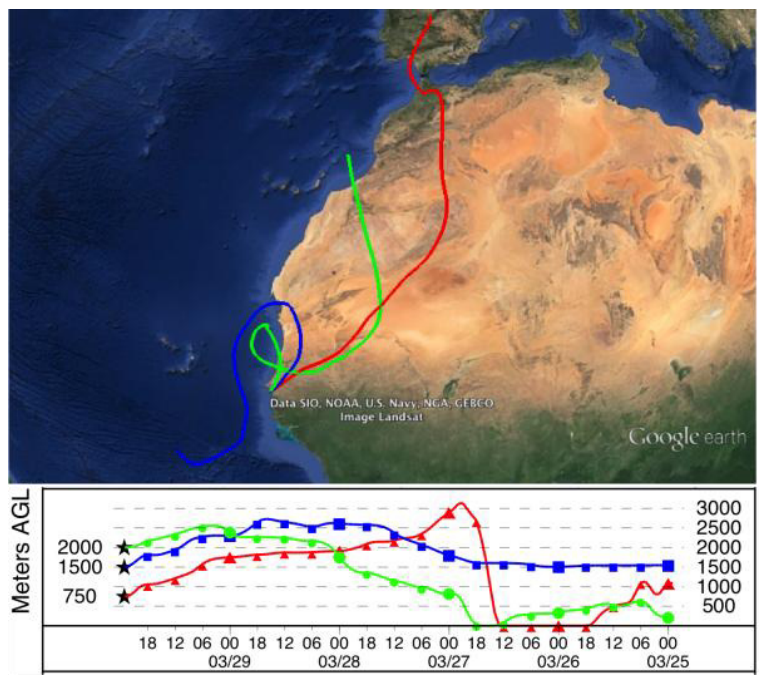

Fig.3. Five-day backward trajectories for the air mass in Mbour at altitudes $750 \mathrm{~m}, 1500 \mathrm{~m}, 2000 \mathrm{~m}$ on 29 March 2015 at 23:00 UTC.

The $A_{355 / 532}^{\beta}$ (BAE) is negative with a minimum value of less than -0.8 , while EAE is still close to 0 as was observed on 13 March. The negative values of BAE observed on 29 March can be the result of the spectral dependence of the imaginary part of the dust refractive index (RI). It is well known that the imaginary part of RI of dust increases in the UV spectral region compared to that at $532 \mathrm{~nm}$ wavelength [3]. The ground based measurements performed during the SAMUM campaign demonstrated that the imaginary part of the dust RI could vary from $\mathrm{m}_{\mathrm{I}}=0.005$ at $532 \mathrm{~nm}$ to $\mathrm{m}_{\mathrm{I}}=0.02$ at $355 \mathrm{~nm}$ [3]. Such a strong enhancement of $\mathrm{m}_{\mathrm{I}}$ may lead to a decrease of the backscattering coefficient [5].

To estimate the impact of the $\mathrm{m}_{\mathrm{I}}$ enhancement at 355 $\mathrm{nm}$ on the values of EAE and BAE at $355 / 532 \mathrm{~nm}$ wavelengths, numerical simulations were performed. Extinction and backscattering Ångström exponents were calculated using the model of randomly oriented spheroids as described in [5] for a bimodal particle size distribution:

$$
\frac{d n(r)}{d \ln (r)}=\sum_{i=f, c} \frac{N_{i}}{(2 \pi)^{1 / 2} \ln \sigma_{i}} \exp \left[-\frac{\left(\ln r-\ln r_{i}\right)^{2}}{2\left(\ln \sigma_{i}\right)^{2}}\right]
$$

where $N_{f, c}$ is particle number density in the fine $(f)$ and the coarse $(c)$ mode. Each mode is represented by a lognormal distribution with modal radius $r_{f, c}$ and dispersion $\ln \sigma_{f, c}$. For the fine mode the values $r_{f}=0.1 \mu \mathrm{m}, \ln \sigma_{f}=0.4$ were used. For the coarse mode $r_{c}=1.0 \mu \mathrm{m}$ and three values $\ln \sigma_{c}=0.4,0.5,0.6$ were considered.
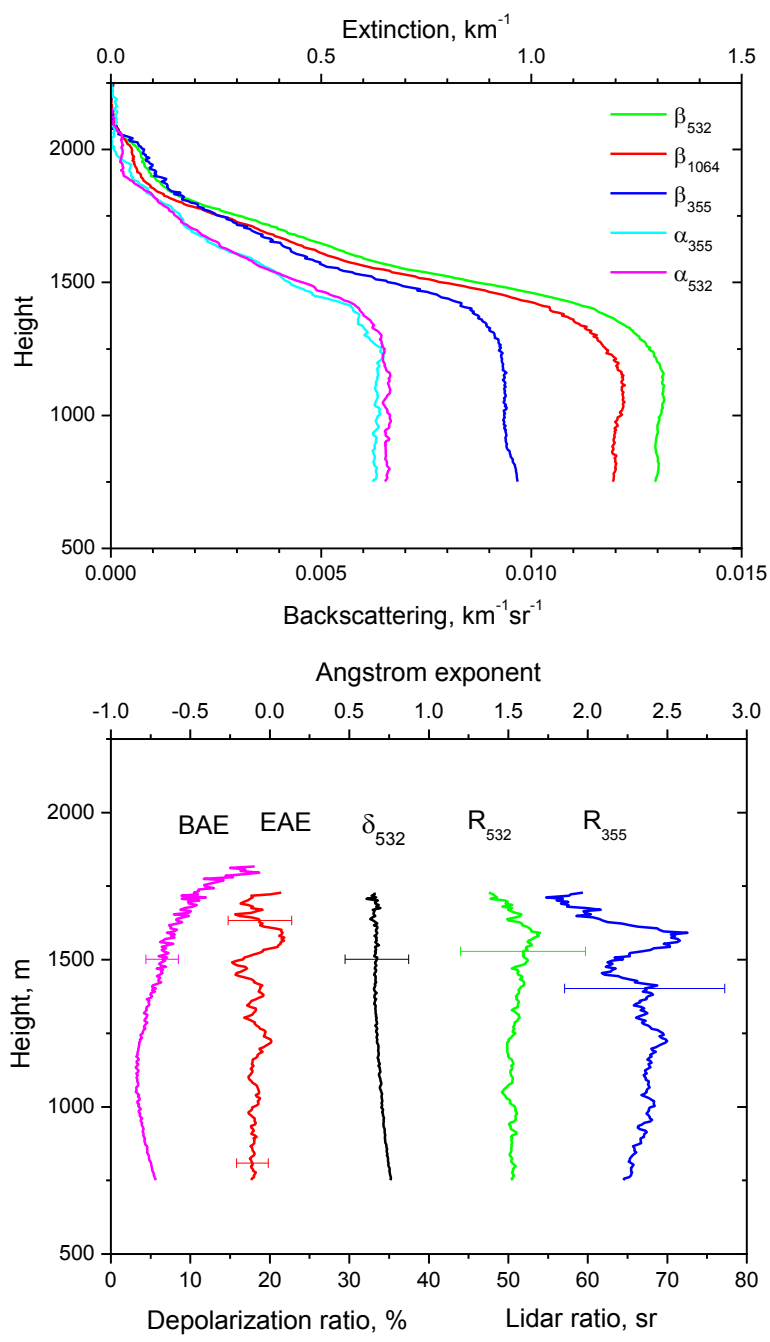

Fig.4. Vertical profiles of (a) backscattering and extinction coefficients and (b) lidar ratios, depolarization ratio, backscattering and extinction Angstrom exponents measured on 29 March 2015 for period 22:00-23:30 UTC.

Three size distributions used in computations are shown as insert in fig.5. The ratio $\mathrm{N}_{\mathrm{c}} / \mathrm{N}_{\mathrm{f}}$ in all cases was 0.01 , and the real part of CRI was 1.55 for all 
wavelengths. The imaginary part was fixed at 0.005 for $532 \mathrm{~nm}$ while it varied within the $0.005-0.05$ range at $355 \mathrm{~nm}$. Values of EAE and $\mathrm{BAE}$ as a function of $m_{I}$ at $355 \mathrm{~nm}$ are given by fig.5. The EAE shows no significant sensitivity to changes in $\mathrm{m}_{\mathrm{I}}$, but BAE decreases rapidly with an increase of $\mathrm{m}_{\mathrm{I}}$ at $355 \mathrm{~nm}$. Although the present sensitivity study is limited, it illustrates the importance of accounting for the spectral dependence of $m_{I}(\lambda)$ in the analyses such as this.

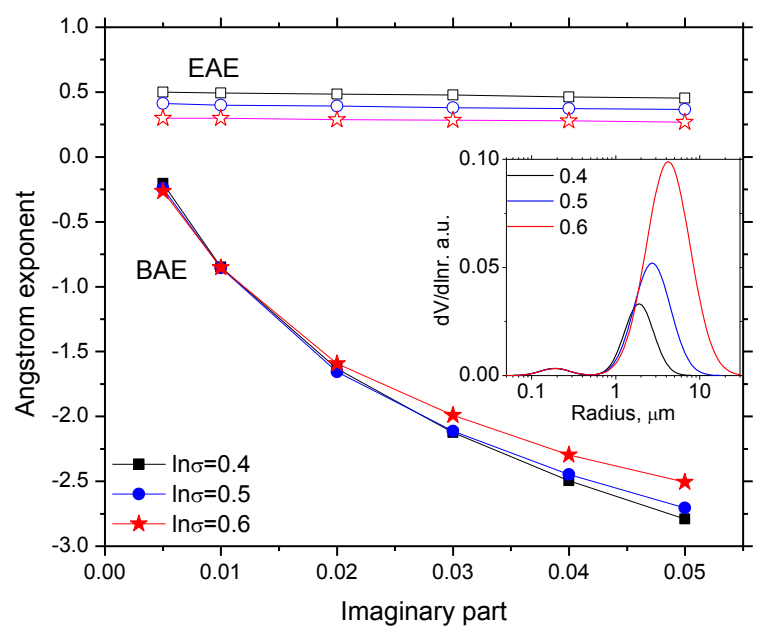

Fig.5. Extinction and backscattering Angstrom exponent for $355 / 532 \mathrm{~nm}$ wavelengths as a function of the imaginary part of the refractive index at $355 \mathrm{~nm}$. The CRI at $532 \mathrm{~nm}$ was kept $\mathrm{m}=1.55-\mathrm{i} .005$. Computations were performed using the model of randomly oriented spheroids for three bimodal PSDs shown in the insert.

\section{CONCLUSION}

The lidar measurements performed in March-April 2015 during the first phase of the SHADOW campaign in Senegal has provided a significant amount of information about dust particle parameters. The use of rotational Raman scattering in the LILAS for $532 \mathrm{~nm}$ observations improved the $\alpha_{532}$ measurements and, as a result, the calculation of lidar ratio and extinction Angstrom exponent were improved as well. The mean values of lidar ratios of pure dust were about $53 \pm 8 \mathrm{sr}$ for both $532 \mathrm{~nm}$ and $355 \mathrm{~nm}$ wavelengths, which agrees with the values observed during SAMUM 1 (Morocco) and SAMUM 2 (Cape Verde) campaigns [3]. The mean value of particle depolarization ratio at $532 \mathrm{~nm}$ was $30 \pm 4.5 \%$, however during strong dust episodes this ratio increased up to $35 \pm 5 \%$, which is also in agreement with the results of SAMUM campaigns. The backscattering Angstrom exponent at 355/532 nm wavelengths during the dust episodes decreased to -
0.7, while the EAE values, though being negative, were higher than -0.2. Low values of BAE may be a result of enhanced dust absorption at $355 \mathrm{~nm}$.

Acknowledgments: Authors thank labex CaPPA for supporting this campaign and are very grateful to IRD-Dakar (Institut de Recherche pour le Développement) and specially A. Diallo and $\mathrm{T}$. Ndiaye for their welcome and efficient support.

\section{References}

[1]. Reid, J. S. and Maring, H. B: Foreword to special section on the Puerto Rico Dust Experiment (PRIDE), J. Geophys. Res. 108, 8585, doi:10.1029/2003JD003510, 2003.

[2] Tanre, D., Haywood, J., Pelon, J., Leon, J.-F., Chatenet, B., Formenti, P., Francis, P., Goloub, P., Highwood, E. J., Myhre, G.: Measurements and modeling of the Saharan dust radiative impact: overview of the Saharan Dust Experiment (SHADE). J. Geophys. Res. 108, 8574, doi:10.1029/2002JD003273, 2003.

[3]. Ansmann, A., Petzold, A., Kandler, K., Tegen, I., Wendisch, M., Müller, D., Weinzierl, B., Müller, T., Heintzenberg, J.: Saharan Mineral Dust Experiments SAMUM-1 and SAMUM-2: what have we learned?, Tellus, 63B, 403-429, 2011.

[4]. Veselovskii, I., Whiteman, D. N., Korenskiy, M., Suvorina, A., Perez-Ramirez, D.: Use of rotational Raman measurements in multiwavelength aerosol lidar for evaluation of particle backscattering and extinction, Atmos. Meas. Tech., 8, 4111-4122, 2015.

[5]. Veselovskii I., O. Dubovik, A. Kolgotin, T. Lapyonok, P. Di Girolamo, D. Summa, D. N. Whiteman, M. Mishchenko, and D. Tanré, 2010: Application Of Randomly Oriented Spheroids For Retrieval Of Dust Particle Parameters From Multiwavelength Lidar Measurements, J. Geophys. Res., 115, D21203, doi:10.1029/2010JD014139, 2010. 